\title{
PENGARUH AKTIFITAS FISIK DAN CEMAS TERHADAP AKTIVITAS SEKSUAL PADA IBU MENOPAUSE DI KECAMATAN MUARA DUA KOTA LHOKSEUMAWE
}

\author{
Nurmila, Jasmiati, Elizar \\ Program Studi D-III Kebidanan, Poltekkes Kemenkes Aceh Utara \\ E-mail : milaabubakar75@gmail.com; jasmiatif@yahoo.com; elizar.ibrahim@yahoo.com
}

\begin{abstract}
The decline as the effect of menopause will cause the decline in various body system, including the decline in mothers' sexuality. It can happen when there are physical change, psychological change, the lack of information and knowledge of the change in mothers, and people's negative perception on sexuality in old age. The objective of the research was to analyze factors physical activit, and apprehensiveness, which influenced sexual activity of menopause mothers in Muara Dua Subdistrict, Lhokseumawe. The research used observational method with cross sectional design. The population was all menopause mothers who still had spouses and lived in Muara Dua Subdistrict, and 82 of them were used as the samples. The data were analyzed by using univatriate analysis, bivatriate analysis. The result of the research showed that of 82 respondents, $56.1 \%$ of them were not sexually active. The result of chi square statistic test showed that the variables of physical activities and apprehensiveness $(p<0.001)$. It is recommended that menopause mothers should keep the health and bodies fresh, decrease physical activities by cooperating with families, especially husbands and should be willing to tell about sexuality in the menopause period to decrease apprehensiveness. Mothers and their husbands should have good perception on sexual activity during menopause so that they can increase their sexual life during menopause.
\end{abstract}

Keywords : Physical Activity, Apprehensiveness, Sexual Activity, Menopause Women

\begin{abstract}
Abstrak
Kemunduran akibat masa menopause akan membawa dampak pada penurunan berbagai sistim tubuh termasuk penurunan seksualitas ibu. Penurunan seksualitas pada ibu menopause dapat terjadi karena adanya perubahan pada fisik. Jenis penelitian adalah observasional dengan pendekatan Cross-sectional. Penelitian ini bertujuan menganalisis hubungan aktivitas fisik dan cemas terhadap aktivitas seksual pada ibu menopause. Populasi pada penelitian ini adalah semua ibu menopause yang ada di kecamatan Muara Dua sebanyak 544 orang. Sampel dalam penelitian ini diambil berdasarkan rumus Lameshow dengan jumlah sampel 82 orang. Analisis data menggunakan analisis univariat, analisis bivariat dengan uji Chi-squre. Hasil penelitian dengan uji Chi-square menunjukkan hasil bahwa aktivitas fisik dan cemas sangat berpengaruh terhadap aktivitas seksual yaitu $(\mathrm{p}<0,001)$. Disarankan kepada tenaga kesehatan terutama bidan dan perawat yang bertugas di Puskesmas terutama saat kegiatan di luar gedung agar dapat melakukan komunikasi, memberikan informasi dan edukasi terutama tentang aktivitas seksualitas masa menopause.
\end{abstract}

Kata kunci : Aktivitas Fisik, Cemas, Aktivitas Seksual, Masa Menopause

\section{PENDAHULUAN}

Usia harapan hidup wanita lebih panjang dibandingkan dengan pria, maka jumlah penduduk lanjut usia wanita lebih banyak dibanding pria. Umur harapan hidup laki laki yaitu 67.98 dan usia harapan hidup perempuan yaitu 71,85.oleh karena itu, permasalahan lanjut usia secara umum di Indonesia sebenarnya tidak lain adalah 
permasalahan yang didominasi oleh wanita (BPS, 2017).

$$
\text { Wanita menghadapi masalah }
$$

kesehatan lebih rumit dari pada pria. Secara kodrati, wanita mengalami fase perubahan fisiologis yang berbeda dengan pria. Mengawali masa remajanya, wanita mulai mengalami menstruasi yang kemudian secara normal terjadi setiap bulan selama masa usia reproduktif. Selanjutnya, mereka akan menjalani masa hamil dan menyusui yang melelahkan. Fase ini diakhiri dengan datangnya masa menopause yang umumnya terjadi pada usia 45 -55 tahun (Siagian, 2014). Menopause disebut juga sebagai periode klimakterium,dimana seorang wanita akan mengalami berhentinya secara definitif mentruasi. Pada fase ini banyak terjadi perubahan dalam fungsi psikis dan fisik, vitalitas tubuh semakin mundur dan menurun. Proses penuaan ini tidak bisa dihindari oleh siapapun karena terjadi secara progresif,perlahan dan pasti (Kartono,2007).

Usia menopause merupakan usia bagi seorang wanita untuk bebas beraktifitas dalam berbagai aspek kehidupannya , akan tetapi hal tersebut menjadi hal yang mengganggu dan menakutkan bila diperhadapkan pada penurunan organ dan fungsi reproduksi yang berdampak pada perubahan aktifitas seksual. Kehidupan seksual merupakan bagian dari kehidupan manusia, sehingga kualitas kehidupan seksual ikut menentukan kualitas kehidupan seorang wanita. Hubungan seksual yang sehat adalah hubungan seksual yang dikehendaki, dapat dinikmati bersama pasangan suami istri dan tidak menimbulkan akibat buruk baik secara fisik maupun secara psikis (Martaadisoebrata dkk,2005).

Keinginan untuk melakukan aktifitas seksual menurun pada masa menopause, pada dasarnya disebabkan wanita menopause mengalami perubahan fisik yaitu kekurangan hormon esterogen yang mengakibatkan vagina mengkerut dan produksi lendirnya berkurang, vagina menjadi kering dan muncul rasa perih saat senggama. Rasa perih saat bersenggama menyebabkan menurunnya libido seorang wanita pada usia menopause,faktor yang berkaitan dengan penurunan libido pada wanita begitu kompleks termasuk hot flushes (semburat panas), gelisah, keringat pada malam hari. Semuanya merupakan gejala umum masa menopause. Wanita yang mengalami hot flushes (semburat panas) dapat menggangu tidur dan bila kurang tidur dapat mengurangi energi dalam melakukan aktifitas seksual dengan pasangannya (Northrup, 2016).

Hubungan seksual dalam keluarga merupakan puncak keharmonisan dan kebahagian, oleh karena itu kedua pihak harus dapat menikmatinya bersama. Ketidakpuasan seks dapat menimbulkan perbedaan pendapat, perselisihan dan akhirnya perceraian. Aktifitas seksual merupakan hubungan intim yang dilakukan oleh suami dan istri atau melakukan kegiatan seksual yang merupakan ungkapan kasih sayang dan rasa cinta, menjalin kehangatan dan perasaan secara menyeluruh pada suami istri (Stuart, 2006 ). Aktifitas seksual membutuhkan tenaga, dengan terkurasnya tenaga usai bekerja atau kurang istiharat, gairah seksualitas menurun karena kelelahan. Fenomena ini sering terjadi dalam rumah tangga dan menjadi alasan bagi wanita untuk menolak melakukan hubungan seks dengan pasangannya.

Hubungan seksual merupakan suatu yang sangat sensitif untuk dibicarakan, namun merupakan hal yang sangat berpengaruh terhadap keharmonisan keluarga. Masalah seksual dalam keluarga merupakan suatu yang sangat penting dan wanita Aceh umumnya tidak mempermasalahkan seksualitas dalam keluarga, karena kebutuhan seksualitas itu merupakan kebutuhan yang memang harus dipenuhi dan mereka menganggap memenuhi kebutuhan seksualitas suami adalah ibadah. Penurunan aktivitas seksual terjadi karena mereka sering merasa kelelahan karna aktivitas sehari hari yang mereka lakukan dan perasaan takut sakit pada saat melakukan hubungan seksual.

\section{METODE PENELITIAN}

Rancangan penelitian yang digunakan adalah observasional dengan pendekatan Cross sectional untuk mendapatkan pengaruh aktivitas fisik dan cemas terhadap aktifitas seksual, dimana subyek diobservasi satu kali 
saja dengan pengukuran variabel bebas dan variabel terikat dilakukan pada saat pengkajian kepada ibu menopause yang masih mempunyai pasangan hidup. Penelitian ini telah dilaksanakan di 17 desa yang ada pada Kecamatan Muara Dua kota Lhokseumawe dan penelitian dilaksanakan mulai tanggal 16 Juni sampai dengan 15 Juli 2019.

Populasi pada penelitian ini adalah seluruh ibu yang berumur 50-60 tahun yang sudah mengalami menopause dan masih punya pasangan hidup yang ada di 17 desa Kecamatan Muara Dua kota Lhokseumawe dengan jumlah 544 orang. Jumlah sampel dalam penelitian ini sebanyak 82 wanita, dan alokasi sampel untuk masing-masing desa ditentukan dengan teknik proporsional random sampling. Analisa data yang digunakan dalam penelitian ini menggunakan analisis univariat yaitu untuk mendapatkan gambaran tentang distribusi frekuensi pada variabel umur, pendidikan, usia perkawinan, aktivitas fisik, cemas dan aktivitas seksual, serta menggunakan analisis bivariat yaitu untuk melihat sejauhmana pengaruh aktivitas fisik dan cemas dengan aktivitas seksual dengan menggunakan uji statistik Chi Square.

\section{HASIL PENELITIAN}

Tabel 1. Distribusi Frekuensi Karakteristik Ibu Menopause Berdasarkan Kelompok Umur di Kecamatan Muara Dua Kota Lhokseumawe

\begin{tabular}{cccc}
\hline No & Umur & n & $\begin{array}{c}\text { Persentase } \\
(\boldsymbol{\%})\end{array}$ \\
\hline 1 & $50-55$ tahun & 38 & 46,3 \\
2 & $56-60$ & 44 & 53,7 \\
\hline & Jumlah & $\mathbf{8 2}$ & $\mathbf{1 0 0}$
\end{tabular}

Berdasarkan tabel 1 mayoritas kelompok umur responden berada pada kelompok 56-60 tahun yaitu 44 orang.

Tabel 2. Distribusi Frekuensi Karakteristik Ibu Menopause Berdasarkan Pendidikan di Kecamatan Muara Dua Kota Lhokseumawe

\begin{tabular}{clcc}
\hline No & Pendidikan & n & $\begin{array}{c}\text { Persentase } \\
(\mathbf{\%})\end{array}$ \\
\hline 1 & $\begin{array}{l}\text { Pendidikan } \\
\text { Tinggi }\end{array}$ & 2 & 2,4 \\
& &
\end{tabular}

\begin{tabular}{clcc}
2 & $\begin{array}{l}\text { Pendidikan } \\
\text { Menengah } \\
\text { Pendidikan } \\
\text { Dasar }\end{array}$ & 66 & 80,5 \\
\hline & Jumlah & $\mathbf{8 2}$ & $\mathbf{1 0 0}$ \\
\hline
\end{tabular}

Berdasarkan tabel 2 pendidikan responden paling dominan pada kategori pendidikan dasar yaitu 14 orang $(17.1 \%)$.

Tabel 3. Distribusi Frekuensi Karakteristik Ibu Menopause Berdasarkan Usia Perkawinan di Kecamatan Muara Dua Kota Lhokseumawe

\begin{tabular}{cccc}
\hline No & Usia Perkawinan & n & $\begin{array}{c}\text { Persentase } \\
(\mathbf{\%})\end{array}$ \\
\hline 1 & $16-25$ tahun & 11 & 13,4 \\
2 & $26-35$ tahun & 40 & 48,8 \\
3 & $36-45$ tahun & 31 & 37,8 \\
\hline & Jumlah & $\mathbf{8 2}$ & $\mathbf{1 0 0}$ \\
\hline
\end{tabular}

Tabel 3 menunjukkan hasil bahwa usia perkawinan paling mayoritas pada ibu menopause di kecamatan Muara Dua adalah pada kategori 26 - 35 tahun yaitu 40 orang $(48,8 \%)$

Tabel 4. Distribusi Frekuensi Aktivitas Fisik Ibu Menopause di Kecamatan Muara Dua Kota Lhokseumawe

\begin{tabular}{llcc}
\hline No & Aktivitas Fisik & n & $\begin{array}{c}\text { Persentase } \\
(\mathbf{\%})\end{array}$ \\
\hline 1 & Ringan & 38 & 46,3 \\
2 & Berat & 44 & 53,7 \\
\hline \multicolumn{2}{c}{ Jumlah } & $\mathbf{8 2}$ & $\mathbf{1 0 0}$ \\
\hline
\end{tabular}

Berdasarkan pengolahan data hasil penelitian pada aktivitas fisik ibu menopause terdapat aktivitas berat yang paling dominan yaitu 44 responden $(53,7 \%)$ sesuai dengan tabel 4.

Tabel 5. Distribusi Frekuensi Cemas Ibu Menopause di Kecamatan Muara Dua Kota Lhokseumawe

\begin{tabular}{clcc}
\hline No & Cemas & n & $\begin{array}{c}\text { Persentase } \\
(\boldsymbol{\%})\end{array}$ \\
\hline 1 & Tidak cemas & 46 & 56,1 \\
2 & Cemas & 36 & 43,9 \\
\hline & Jumlah & $\mathbf{8 2}$ & $\mathbf{1 0 0}$ \\
\hline
\end{tabular}


Berdasarkan tabel 5.dapat dilihat bahwa mayoritas Ibu Menopause tidak Merasakan cemas yaitu 46 orang ( 56,1\%).

Tabel 6. Distribusi Frekuensi Aktivitas Seksual Ibu Menopause di Kecamatan Muara Dua Kota Lhokseumawe

\begin{tabular}{llcc}
\hline No & Aktivitas seksual & n & $\begin{array}{c}\text { Persentase } \\
(\mathbf{\%})\end{array}$ \\
\hline 1 & Aktif & 36 & 43,9 \\
2 & Tidak aktif & 46 & 56,1 \\
\hline \multicolumn{2}{c}{ Jumlah } & $\mathbf{8 2}$ & $\mathbf{1 0 0}$ \\
\hline
\end{tabular}

Tabel 6 diatas menunjukan bahwa ibu menopause tidak aktif secara seksual sebanyak 46 orang $(56,1 \%)$.

Tabel 7. Pengaruh Aktivitas Fisik dengan Aktivitas Seksual pada Ibu Menopause di Kecamatan Muara Dua Kota Lhokseumawe

\begin{tabular}{|c|c|c|c|c|c|c|c|}
\hline \multirow{3}{*}{ No } & \multicolumn{5}{|c|}{ Aktivitas Seksual } & \multirow[b]{2}{*}{ Jumlah } & \multirow[b]{2}{*}{$\mathbf{p}$} \\
\hline & $\begin{array}{l}\text { Aktivitas } \\
\text { Fisik }\end{array}$ & \multicolumn{2}{|c|}{ Aktif } & \multicolumn{2}{|c|}{$\begin{array}{l}\text { Tidak } \\
\text { Aktif }\end{array}$} & & \\
\hline & & $\mathrm{n}$ & $\%$ & $\mathbf{n}$ & $\%$ & n $\%$ & \\
\hline 1 & Ringan & 25 & 65,8 & 13 & 34,2 & $3810 C$ & \\
\hline 2 & Berat & 11 & 25,0 & 33 & 75,0 & 44100 & 0,001 \\
\hline
\end{tabular}

Dari tabel 7 dapat dilihat bahwa ibu dengan aktivitas fisik berat $75 \%$ tidak aktif secara seksual. Dan hasil uji ststistik menunjukkan bahwa ada hubungan yang signifikan antara aktifitas fisik dengan aktifitas seksual.

Tabel 8. Pengaruh Cemas dengan Aktivitas Seksual pada Ibu Menopause di Kecamatan Muara Dua Kota Lhokseumawe

\begin{tabular}{|c|c|c|c|c|c|c|c|}
\hline \multirow{3}{*}{ No } & \multirow{3}{*}{ Cemas } & \multicolumn{4}{|c|}{ Aktivitas Seksual } & \multirow[b]{2}{*}{ Jumlah } & \\
\hline & & \multicolumn{2}{|c|}{ Aktif } & \multicolumn{2}{|c|}{$\begin{array}{l}\text { Tidak } \\
\text { Aktif }\end{array}$} & & $\mathbf{p}$ \\
\hline & & $\mathbf{n}$ & $\%$ & $\mathbf{n}$ & $\%$ & n $\%$ & \\
\hline 1 & $\begin{array}{l}\text { Tidak } \\
\text { Cemas }\end{array}$ & 29 & 63,0 & 17 & 37,0 & 46100 & \\
\hline 2 & Cemas & 7 & 19,4 & 29 & 80,6 & 36100 & \\
\hline
\end{tabular}

Berdasarkan tabel 8 tergambar bahwa ibu yang cemas tidak aktif secara seksual 80,6 $\%$ dan hassil uji terlihat bahwa ada hubungan yang signifikan antara cemas dengan aktivitas seksual.

\section{PEMBAHASAN}

\section{Karakteristik Ibu Menopause}

Hasil penelitian dapat kita lihat bahwa Umur ibu menopause lebih dominan pada umur 50- 56 dengan usia perkawinan paling lama pada 25 -35 tahun. Usia ibu akan membuat ibu lebih siap dalam menghadapi perubahan perubahan yang akan terjadi pada masa menopause sehingga akan lebih mudah beradaptasi dengan kemunduran yang akan terjadi pada ibu terutama terhadap organ reproduksinya. Lamanya usia perkawianan akan membuat ibu menjadi lebih faham dan mampu beradaptasi dengan perubahan fisiknya terutama kesiapan fisiknya dalam memenuhi kebutuhan seksualitas. pada tingkat pendidikan ibu menopause dominan pada tingkat pendidikan dasar yaitu tamat SD dan SMP sebanyak 80,5\% .Tingkat pendidikan seseorang akan memberikan pengaruh terhadap proses penerimaan informasi dan penyerapan informasi. Tingkat pendidikan merupakan pencerminan dari tingkat sosial masyarakat dan individu dimana tingkat pendidikan seseorang juga sangat mempengaruhi tingkat pengetahuan seseorang.

\section{Aktivitas Seksual}

Analisis penelitian pada variabel aktivitas seksual pada ibu menopause menunjukkan dari 82 ibu menopause, mayoritas ibu dengan aktivitas fisik berat 44 ibu menopause $(53,7 \%)$ dan aktivitas fisik ringan 38 ibu menopause, hal ini menunjukan bahwa banyak ibu-ibu menopause yang melakukan kegiatan sehari-harinya sendiri, hal ini membuat kelelahan pada tubuh ibu yang berdampak pada aktivitas seksualnya. Menurut Gunarsa (2012) penurunan gairah seksual pada wanita menopause dapat di sebabkan karena terlalu sibuk dengan pekerjaan sehari-hari yang dapat menimbulkan kelelahan fisik dan ini merupakan alasan paling utama dalam rumah tangga untuk menolak melakukan hubungan seksual dengan suami karena pada dasarnya aktivitas seksual membutuhkan tenaga, pada saat tenaga itu terkuras akibat 
kegiatan fisik sehari-hari maka akan menyebabkan terjadinya penurunan gairah seksualitas, hal ini sesuai dengan hasil penelitian dimana ibu dengan aktivitas berat mengalami penurunan dalam melakukan aktivitas seksual. Banyak ibu-ibu yang hanya kadang-kadang atau tidak menentu melakukan aktivitas seksual padahal pada wanita menopause kerutinan melakukan hubungan seksual merupakan hal yang sangat penting diperhatikan dan merupakan salah satu cara untuk menghindari terjadinya kekakuan otot vagina yang menjadi penyebab rasa sakit dan nyeri saat berhubungan.

\section{Aktivitas fisik}

Hasil uji statistik terhadap pengaruh aktivitas fisik dengan aktivitas seksual menunjukkan bahwa ibu dengan aktivitas fisik berat tidak aktif melakukan aktivitas seksual sebanyak 33 ibu menopause $(75,0 \%)$ dan ibu menopause dengan aktivitas fisik ringan tidak aktif melakukan aktivitas seksual sebanyak 13 ibu menopause $(37,0 \%)$ dan uji statistik ChiSquare diperoleh nilai $p<0,001$ membuktikan bahwa ada hubungan yang signifikan antara aktivitas fisik dengan aktivitas seksual pada ibu menopause .

Menurut Darmojo dan Martono (2016), faktor yang memengaruhi aktivitas seksual pada wanita menopause adalah faktor internal berupa perubahan dan kemunduran fisik yang berkaitan dengan hormon seks yang memberikan pengaruh pada penurunan seksualitas wanita menopause.

Secara psikologis seksualitas berhubungan erat dengan identitas peran jenis, perasaan terhadap seksualitas itu sendiri dan bagaimana menjalankan fungsi sebagai makluk seksual dan juga berkaitan dengan bagaimana lingkungan berpengaruh dalam pembentukan mengenai seksualitas dan prilaku seks menjadi bagian dari kehidupan masyarakat. Hilangnya gairah seksual secara jangka panjang terjadi pada sejumlah wanita selama dan sesudah menopause, penyebab hilangnya gairah seksual pada perempuan menopause atau menurunya libido dapat disebabkan oleh kelelahan.
Pekerjaan sebagai wanita yang mengurus anak dan suami membuat seorang wanita mempunya peran ganda apalagi jika wanita tersebut wanita karier sehingga membuat dirinya mencapai titik kelelahan yang sangat berat ( Mulyani, 2013 ).

Keinginan untuk melakukan aktifitas seksual menurun pada masa menpause, pada dasarnya disebabkan wanita menopause mengalami banyak perubahan fisik dan fungsi tubuh. Penurunan gairah seksual juga sangat dipengaruhi oleh pekerjaan, sehingga menimbulkan kelelahan fisik yang mengakibatkan hubungan seks yang monoton serta terjadi perubahan dorongan seks.Selain itu hubngan seksual merupakan suatu yang sensitif untuk dibicarakan namun sangat mempengaruhi keharmonisan dalam rumah tangga.

Wanita Aceh pada umumnya mempunyai sifat tertutup dan tidak suka membicarakan permasalahan keluarga terutama tentang hubungan seksual pada orang lain. Masalah seksualitas dalam keluarga merupakan suatu yang penting dan tetap harus terpenuhi walaupun terjadi perubahan pada pola hubungan seksualitas itu sendiri. Pada kondisi tertentu ibu ada yang tidak tidur sekamar lagi dengan suami karna merasa malu dan kelelahan. Pekerjaan sehari-hari yang dapat menimbulkan kelekahan fisik dan ini merupakan alasan paling utama dalam rumah tangga untuk menolak melakukan hubungan seksual denga suami karena pada dasarnya aktivitas seksual membutukan tenaga, pada saat tenaga itu terkuras akibat kegiatan fisik sehari-hari maka akan menyebabkan terjadinya penurunan gairak seksualitas.

Hasil penelitian Qamariyah (2013) dengan judul hubungan kecemasan dan aktivitas fisik dengan kehidupan seksual pada wanita menopause di kelurahan Sajen wilayah kerja puskesmas Trucuk I kabupaten Klaten terhadap 81 responden dengan metode survey explanatory dan pendekatan yang digunakan Cross sectional didapatkan hasil mayoritas responden tidak mengalami kecemasan yaitu 98,8\% dan sebagian besar responden yaitu $56,8 \%$ memiliki aktivitas fisik dengan level sedang serta responden yang memiliki 
kehidupan seksual normal sebanyak 74,1\%.Dari hasil uji korelasi Rank Sperman dapat diketahui bahwa kecemasan yang dialami responden tidak memiliki hubungan dengan kehidupan seksual responden saat menopause dengan p-value 0,158 , dan hasil uji Anova dapat diketahui bahwa aktivitas fisik responden menyebabkan adanya perbedaan yang bermakna pada kehidupan seksual responden saat menopause dengan $\mathrm{p}$-value 0,044 .

Hasil Penelitian Widodo (2010) mengungkapkan bahwa pengaruh menopause terhadap aktivitas seksual menjadi kurang bahkan tidak sama sekali melakukan aktivitas seksual karena tidak bergairah lagi dan hasil wawancara pada ibu menopause sebanyak 75 $\%$ responden tidak ada upaya dan keinginan untuk bertanya pada tenaga kesehatan ataupun membaca buku,cukup dengan mendengarkan dari orang lain dan anggapan- anggapan yang ada di masyarakat.

\section{Cemas.}

Perubahan fisik dan perubahan ogran reproduksi yang berdampak pada perubahan seksualitas yang dialami oleh ibu membuat ibu mengalami cemas.Kondisi ini diasumsikan bahwa umur ibu dan lamanya ibu mengalami menopause saat dilakukan penelitian termasuk masih muda sehingga ibu mengalami kesulitan dalam beradaptasi terhadap proses perubahan secara keseluruhan dan ini kondisi membuat ibu mengalami cemas, kecemasan timbul karena adanya rasa kekhawatiran dalam menghadapi situasi yang sebelumnya tidak pernah di khawatirkan, cemas merupakan keadaan yang wajar karena seseorang pasti menginginkan segala sesuatu dalam hidupnya dapat berjalan dengan lancar dan terhindar dari segala bentuk kegagalan serta sesuai dengan harapannya,untuk sampai pada tahap tersebut perlu proses adaptasi. Pada ibu yang tidak mengalami cemas banyak dijumpai pada ibu yang telah berumur 60 tahun dimana ibu sudah mengalami proses adaptasi terhadap perubahan yang dialaminya sehingga tidak membuat ibu cemas .Menurut Phanjoo ( Tahun 2000 ) 70 \% disfungsi seksualitas dipengaruhi karena perubahan psikologis seperti cemas.
Proses menopause terjadi secara tibatiba serta kecepatan perkembanganya tidak tetap, wanita akan mengalami penurunan fungsi tubuh secara bertahap sekitar usia 4555 tahun. Penurunan fungsi tubuh yang terjadi pada wanita usia 45 tahun menyebabkan terjadinya perubahan yang dapat menimbulkan masalah kesehatan seperti hot flashes, keringat dingin, gangguan tidur, perubahan mood, depresi dan mudah tersinggung, terjadi infeksi saluran kemih, inkontinesia urin, peningkatan lemak pada tubuh disekitar pinggang, bermasalah dengan konsentrasi dan daya ingat, tidak berminat pada hubungan seksual dan nyeri pada saat senggama (Kartono, 2007).

\section{KESIMPULAN}

Berdasarkan hasil analisa dan pembahasan hasil penelitian mengenai pengaruh aktivitas fisik terhadap aktivitas seksual bahwa aktivitas seksual pada wanita menopause tidak dipengaruhi oleh umur. Tidak ada hubungan yang signifikan antara umur dengan aktivitas seksual. Pada dasarnya aktivitas seksual masa menopause tidak hilang namun terjadi penurunan pada frekuensinya. Aktivitas fisik dan cemas sangat mempengaruhi ibu terhadap aktivitas seksual. Kegiatan sehari-hari yang dikerjakan oleh ibu dan ketidaknyamanan ibu dalam melakukan hubungan seksual menjadi alasan ibu menolak melakukan hubungan seksual.

\section{SARAN}

Diharapkan kepada ibu-ibu menopause agar menjaga kesehatan dan kebugaran tubuh sehingga tetap dapat menjaga kehidupan seksualitas yang sehat dan berkualitas serta ibu dan suami mempunyai pandangan yang baik terhadap kehidupan seksualitas masa tua agar dapat menjaga keharmonisan dalam rumah tangga dan bagi ibu-ibu menopause dengan aktivitas fisik berat, mau berkonsultasi kepada tenaga kesehatan tentang aktivitas seksual masa menopause serta dapat mengurangi aktivitas fisiknya dengan bekerja sama dengan keluarga terutama suami dan kepada tenaga kesehatan terutama bidan dan perawat yang bertugas di pos-pos pelayanan kesehatan yang ada di desa agar dapat memberikan 
komunikasi, informasi dan edukasi pada ibu menopause dan suami terutama tentang seksulitas pada masa menopause.

\section{REFERENSI}

Badan Pusat Statistik Indonesia. (2019). Penduduk usia lanjut. Jakarta : Depkes RI.

Darmojo. B, Martono, H. (2016). Buku ajar ilmu keperawatan usia lanjut. Jakarta : FK-UI.

Hastuti, L. (2007). Hubungan antara kecemasan dengan aktifitas dan fungsi seksual pada wanita usia lanjut. Jurnal berita kedokteran masyarakat, Vol 24 No 4, Desember 2008

Gunarsa, Y. (2012). Asas-asas psikologi keluarga idaman. Jakarta : PT BPK Gunung mulia.

Kementerian Kesehatan RI. (2010). Pedoman pengelolaan kegiatan kesehatan di kelompok lanjut usia. Jakarta : Kemenkes RI.

Kartono, K. (2007). Psikologi Wanita. Bandung : Mandar maju.

Mc Khann, G \& Albert, M. (2010). Agar otak awet muda. Yokyakarta : Med Press.

Martaadisoebrata. (2005). Bunga rampai obstretri \& genekologi. Jakarta :YBPSP

Northrup, C. (2016). Bijak di saat menopause. Bandung : Penerbit Q-Press.

Nugraha, B. (2014). Kualitas seksual lebih bermakna saat menopause. Dikutip dari http:// gaya hidup. com/read/ detail/ 12299182.

Phanjoo, Y. (2000). Sexual Dysfunction in old age, advances in psychiatric, treatment. Edinburg

Qamariyati, (2013). Hubungan kecemasan dan aktifitas fisik dengan kehidupan seksual pada wanita menopause. Jurnal kesehatan Masyarakat, Vol 2 No 1, Januari 2013

Siagian, A. (2014). Saatnya memperhatikan kesehatan wanita usia menopause dengan serius. Dikutip dari www Kesrepro, info, Yogyakarta, Akses 12 Februari 2014

Suparto, H. (2006). Sehat menjelang usia senja. Bandung : PT Remaja Rosda Karya.
Stuart, G.N., \& Sundeen, S.J. (2006). Buku saku keperawatan jiwa. Jakarta : EGC

Ulfiana. (2014). Konseling pasangan suami istri tentang aktivitas seksual pada wanita menopause. 